\title{
Effect of treatment of malignant disease on growth in children
}

\author{
N K GRIFFIN AND JANE WADSWORTH
}

St Bartholomew's Hospital, London

SUMMARY The growth of 95 children with malignant disease was studied over a 3- or 4-year period, and compared with the growth of normal children matched for age and sex by calculation of the standard deviation score. The mean standard deviation score of the children with leukaemia fell in the first year of treatment, and thereafter showed little change, remaining below the normal. This effect was related to cranial cnd craniospinal irradiation, but not to age or duration of chemotherapy. The loss in eventual height attained was small and does not suggest any long-term interference with growth hormone production.

In recent years it has become possible, and increasingly necessary, to study the long-term effects of the treatment of malignant disease in childhood. ${ }^{1}$ Short stature as a late complication of cranial irradiation has been described ${ }^{2}$ and is associated with growth hormone (GH) deficiency, the degree of which is related both to the dose of irradiation given to the pituitary region, and to the length of time since the irradiation was given. ${ }^{2-3}$ The duration of the radiation course also affects the degree of $\mathbf{G H}$ deficiency.

Spinal irradiation may cause an inhibition of growth due to the effect of radiation on growing bone. ${ }^{4}$

However, there are no published reports to indicate what proportion of children receiving cranial irradiation fail to grow normally, and to what degree they may be affected. In this series the heights of 95 children were studied over a 3- or 4-year period and compared with the standard normal heights for age and sex. ${ }^{5}$ The effect of the diagnosis, radiotherapy field, duration of chemotherapy, age at presentation, and patient's sex was studied.

\section{Patients and methods}

The children were attending the paediatric oncology clinic at St Bartholomew's Hospital or The Hospital for Sick Children, London. Any child who had survived more than 3 years since the onset of his disease, who did not have intracerebral disease, and whose notes were sufficiently complete to permit analysis was studied. 95 children were available for study; their diagnoses are shown in Table 1.
Table 1 Diagnoses of 95 patients

\begin{tabular}{lc}
\hline Diagnosis & No of patients \\
\hline Leukaemic group & \multicolumn{2}{c}{65} \\
Acute lymphoblastic leukaemia & 6 \\
Non-Hodgkin's lymphoma & \multicolumn{2}{c}{. } \\
Solid tumour group & 13 \\
Hodgkin's disease & 4 \\
Rhabdomyosarcoma & 3 \\
Ewing's sarcoma & 3 \\
Wilms's tumour & 1 \\
Ganglioneuroblastoma & \\
\hline
\end{tabular}

Children with non-Hodgkin's lymphoma received treatment similar to that given for acute lymphoblastic leukaemia and were included in the leukaemic group.

All but 9 children received megavoltage radiotherapy as an early part of their treatment. 66 children in the leukaemic group had prophylactic treatment of the central nervous system (CNS) with cranial irradiation, of whom 24 also received radiotherapy to the whole spine. The radiotherapy schedules of this group are shown in Table 2. 20 children with solid tumours received radiotherapy to sites that did not include the cranium.

Children in the leukaemic group received chemotherapy according to a Medical Research Council (UKALL I-V), or similar treatment protocol, for between 2 and 4 years. Six children with Hodgkin's disease received no chemotherapy, but all the others in the group with solid tumours received at least 4 months of chemotherapy. 12 patients were treated for 12 months or less, and 6 patients for at least 24 months. 
Table 2 Radiotherapy schedules of 66 patients who received prophylactic central nervous system megavoltage irradiation

\begin{tabular}{|c|c|c|c|c|}
\hline Irradiation & $\begin{array}{l}\text { Dose } \\
\text { (rad) }\end{array}$ & $\begin{array}{l}\text { No of } \\
\text { fractions }\end{array}$ & $\begin{array}{l}\text { Length of course } \\
\text { (days) }\end{array}$ & $\begin{array}{l}\text { No of } \\
\text { patients }\end{array}$ \\
\hline$\left\{\begin{array}{l}\text { Cranial } \\
\text { Spinal }\end{array}\right.$ & $\begin{array}{l}2400 \\
1000\end{array}$ & $\begin{array}{r}20 \\
5\end{array}$ & $\begin{array}{r}28 \\
7\end{array}$ & $20^{*}$ \\
\hline$\left\{\begin{array}{l}\text { Cranial } \\
\text { Spinal }\end{array}\right.$ & $\begin{array}{l}2400 \\
1600-2400\end{array}$ & $\begin{array}{l}20 \\
20\end{array}$ & $\begin{array}{l}28 \\
28\end{array}$ & 4 \\
\hline $\begin{array}{l}\text { Cranial } \\
\text { Cranial } \\
\text { Cranial }\end{array}$ & $\begin{array}{l}2400 \\
2400 \\
1500-2500\end{array}$ & $\begin{array}{l}15 \\
20 \\
13-17\end{array}$ & $\begin{array}{l}21 \\
28 \\
19-24\end{array}$ & $\begin{array}{c}20 \\
18 \dagger \\
4\end{array}$ \\
\hline
\end{tabular}

*2 patients had interruptions of more than 4 days in their treatment, +3 patients had interruptions of more than 4 days in their treatment.

Each child had his height measured at each visit to the clinic. The heights at presentation, at the end of CNS prophylaxis when this was given, and at each anniversary of their presentation were compared with normal values for age and sex, by calculation of the standard deviation (SD) score from the formula $\mathrm{SD}=(\overline{\mathrm{x}}-\mathrm{x}) / \mathrm{SD} \quad(\overline{\mathrm{x}}=$ mean of normal population: $\mathrm{x}=$ the measurement: $\mathrm{SD}=$ standard deviation). ${ }^{6}$ In this way the results are standardised and allow comparison with children of different ages and sexes. The normal population has a mean SD score of 0 with a standard deviation of 1.0.

Any child who had more than one measurement unavailable for analysis was excluded from the study.

Analysis of variance was used in order to assess simultaneously the effects of the diagnosis, treatment, age, and sex on the SD score. The residual standard error from this procedure was used in the comparison of mean SD score by Student's $t$ test.

\section{Results}

The SD scores for groups of patients were analysed to demonstrate differences due to diagnostic group, radiotherapy field, duration of chemotherapy, sex, and age at presentation. Only the diagnosis and the area irradiated were shown to have any significant effect on growth.

Fig. 1 shows the mean SD score of patients categorised according to the diagnostic group acute lymphoblastic leukaemia (including non-Hodgkin's lymphoma) and solid tumours, for 4 years after presentation. At the time of presentation neither group differed significantly from the normal population. The children with solid tumours had a mean height at presentation that was just below the mean for the normal population and it subsequently fell slightly but at no stage was it greatly different from the normal population.

Patients with leukaemia had a mean height at presentation 0.14 SD above the mean for the normal population. It fell between presentation and the

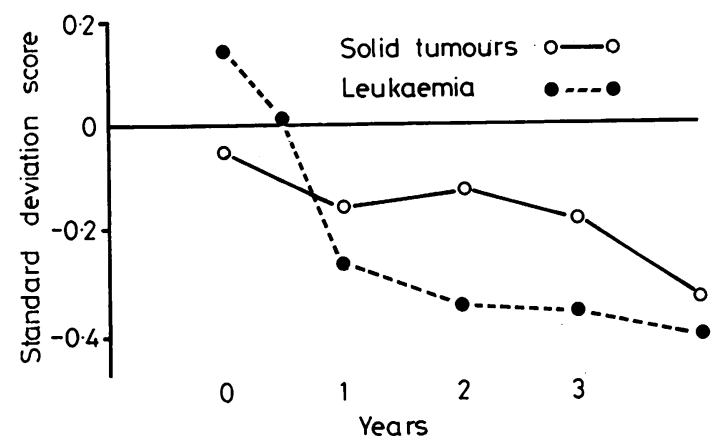

Fig. 1 Mean standard deviation score values for heights of patients with acute lymphoblastic leukaemia (including non-Hodgkin's lymphoma) and solid tumours. Values for the leukaemic children at 1-3 years are significantly lower than the values at presentation $(P<0.001)$.

end of CNS prophylaxis by $0 \cdot 13 \mathrm{SD}$, and by a further $0.28 \mathrm{SD}$ by one year after presentation when it was significantly different from the value at presentation $(P<0.001)$ and from $0(P<0.05)$. During the next 3 years there was no significant change in the mean SD score for this group of patients, but it remained significantly different from $0(P<0.02)$. Only 45 patients with leukaemia and 13 with solid tumours were available for study 4 years after presentation.

Fig. 2 shows the mean SD score of patients

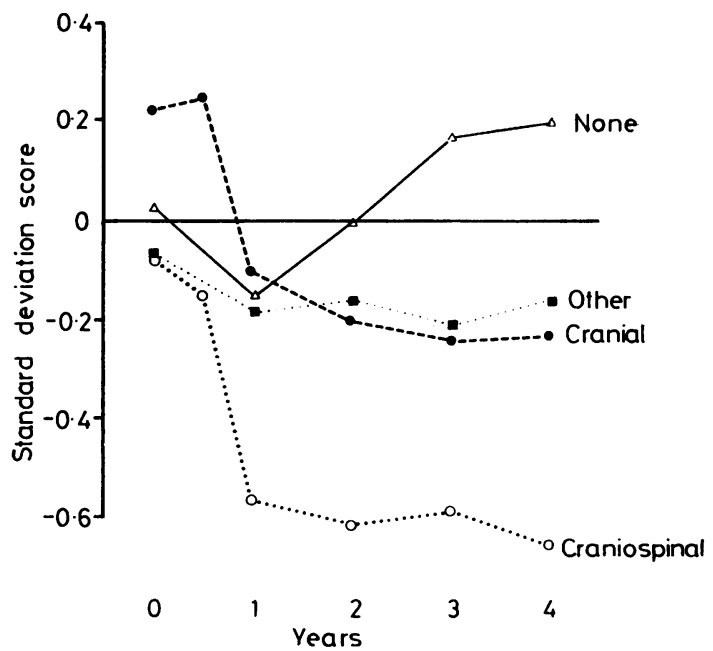

Fig. 2 Mean standard deviation score values for heights of patients grouped according to site of radiotherapy. Values for the cranial and craniospinallyirradiated groups at 1-4 years are significantly lower than the values at presentation $(P<0.001)$. 
categorised according to the site of the radiotherapy. The patients were divided into groups of those who had received cranial irradiation only, those who had received craniospinal irradiation, and those who had received irradiation to other sites. At presentation the mean SD score of all groups did not differ significantly from 0 .

Patients receiving no radiotherapy (9 patients), or radiotherapy to sites outside the CNS (20 patients) showed no significant change in their mean SD score during the period of the study.

Patients who received cranial irradiation showed a growth pattern similar to those who received craniospinal irradiation. There was no significant change in the mean SD score before the end of CNS irradiation, represented by the second point on the graphs, but there was a fall in the mean SD score between that time and one year after presentation. Thereafter the mean SD score showed no further significant change but in both groups it remained different from the value at presentation $(\mathrm{P}<0.001)$.

Patients who received cranial or craniospinal radiotherapy had a mean change in height SD score in the year after presentation of -0.41 (SD 0.59). The range of changes in SD score was wide $(-1.99$ to 1.74), which may reflect inaccuracies in some of the measurements. However there is no reason to believe that this would affect the mean values of a large number of children, since such inaccuracies would tend to cancel each other out when mean values were calculated.

Fig. 3 shows the distribution of the SD scores for the whole leukaemic group at presentation and 3 years later. Each time the distribution was approximately normal, suggesting that the failure to grow in the first year of treatment affected all patients

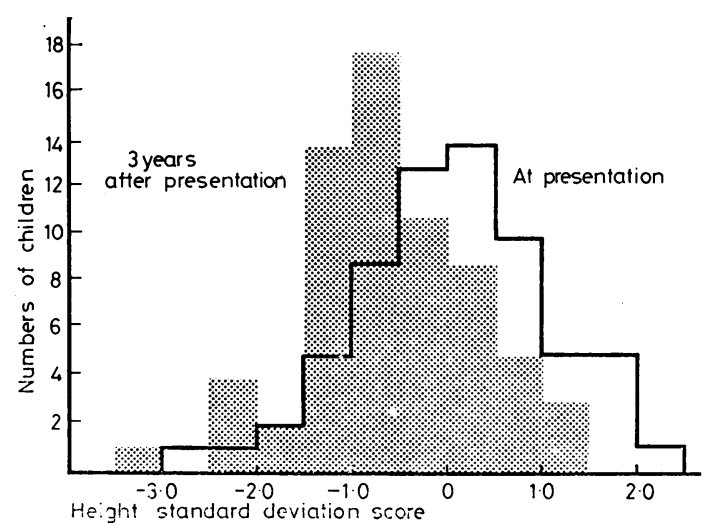

Fig. 3 Distribution of height standard deviation score values for leukaemic patients at presentation and 3 years later. similarly, and that these results were not due to a small group showing severe growth failure. This suggestion was supported by examining the behaviour of individual patients: $58(88 \%)$ of the 66 patients who received cranial or craniospinal irradiation had a decrease in their SD score during the period of the study.

\section{Discussion}

Radiotherapy is cytotoxic not only to malignant but also to normal cells. The degree to which the viability and function of normal cells may be affected by radiation varies with different tissues and the age of the patient. It has been recognised for many years that irradiation of growing bones causes a local inhibition of growth and that high doses of ionising irradiation can cause growth failure. Workers in Manchester showed a range of endocrine disturbances in some children after therapeutic irradiation of the pituitary region for treatment of brain tumours or after CNS prophylaxis in leukaemic children, ${ }^{2-3}$ and it was suggested that the threshold for impairment of $\mathrm{GH}$ production is a radiation dose to the pituitary region of 2900 rad over 3 weeks. ${ }^{\text {? }}$ However, the clinical importance of these observations has remained uncertain, as the incidence and degree of short stature after CNS prophylaxis for leukaemia has not been reported.

The GH deficiency described in patients after cranial irradiation represents a blunting of the peak level achieved after insulin or Bovril provocation. While these findings confirm an interference with GH production, the GH deficiency is not always so profound as necessarily to cause an impairment of growth. ${ }^{8}$

The criterion for the diagnosis of GH deficiency is conventionally taken as the inability to produce a serum GH level $>20 \mathrm{mU} / \mathbf{l}$ after adequate provocation. However, this arbitrary level is not universally accepted and Frasier ${ }^{8}$ suggested that replacement therapy was unlikely to be effective if the $\mathrm{GH}$ level rose above $14 \mathrm{mU} / \mathrm{l}$.

In the series of Shalet et al. ${ }^{9}$ reporting GH studies in 15 children after cranial irradiation for leukaemia, a maximum $\mathrm{GH}$ level $>14 \mathrm{mU} / 1$ was achieved in all but one child, and he had received 2500 rad to the cranium in 10 fractions over 14 days; this dose has a greater biological effect than that which is generally used for CNS prophylaxis in childhood leukaemia.

Dacou-Voutetakis et al. ${ }^{10}$ reported that spontaneous nocturnal GH secretion was impaired immediately after cranial irradiation in leukaemic children but recovered within 6-12 months. However, Shalet et al..$^{2}$ suggested that after irradiation for intracranial tumours $\mathrm{GH}$ response to 
stimulation decreased with time since treatment, but their patients received higher doses of radiation, and other factors-such as raised intracranial pressure-may have affected pituitary function.

Our results demonstrate that patients receiving radiotherapy to the CNS may have an inhibition of normal growth in the period after the radiotherapy. The timing of the growth failure is compatible with the transient depression of GH levels observed by Dacou-Voutetakis et al. ${ }^{10}$ These effects are due to cranial radiotherapy, because patients who received radiotherapy to other sites and had systemic chemotherapy grew at a normal rate; there was no difference in growth pattern in children who had different periods of chemotherapy, and the initial period of treatment in the leukaemic group, when steroid and cytotoxic dosage was highest, was not associated with a reduced growth rate.

Our data suggest that most children receiving such treatment are affected and there is no evidence to suggest that a small group of children showed severe growth failure. It is possible that more severe growth failure could become manifest in long-term survivors, but in our study the growth rate was reduced only in the first year after presentation, and was normal thereafter. It is notable that there was no evidence of 'catch-up growth' over a 4-year period, and it is unlikely that it would happen after this time.

Although growth failure is observed in patients after CNS prophylaxis in leukaemia, it must be noted that the mean decrease in SD score for patients receiving cranial irradiation is less than 0.5 . The SD of heights for 18-year-old boys is $6.65 \mathrm{~cm}$ and for 16-year-old girls it is $6.0 \mathrm{~cm} .{ }^{5}$ The findings described above therefore suggest that after prophylactic irradiation to the CNS in leukaemic children their eventual height may be decreased by $3-5 \mathrm{~cm}$.

It is recommended that the growth of children with leukaemia should be monitored routinely, and further investigations be performed on the usual clinical criteria if it appears that a child is consistently failing to grow at a normal rate. There appears to be no indication for routine tests of GH secretion, nor is there any reason to believe that GH therapy would be indicated or effective.
We thank Professor $\mathbf{R} \mathbf{M}$ Hardisty and Dr J M Chessells, The Hospital for Sick Children, London, and Dr J S Malpas, Dr J Graham-Pole, and Dr M R Sandland, St Bartholomew's Hospital, for advice and permission to study their patients.

N K G was supported by the Leukaemia Research Fund.

\section{References}

1 Anonymous. The price of survival in childhood leukaemia. Br Med J 1978; i: 321-2.

2 Shalet S M, Beardwell C G, Morris Jones $\mathbf{P} \mathbf{H}$, Pearson D. Pituitary function after treatment of intracranial tumours in children. Lancet 1975; ii: 104-7.

3 Shalet S M, Beardwell C G, MacFarlane I A, Morris Jones P H, Pearson D. Endocrine morbidity in adults treated with cerebral irradiation for brain tumours during childhood. Acta Endocrinol (Kbh) 1977; 84: 673-80.

- Probert J C, Parker B R, Kaplan H S. Growth retardation in children after megavoltage irradiation of the spine. Cancer 1973; 32: 634-9.

5 Tanner J M, Whitehouse R H, Takaishi M. Standards from birth to maturity for height, weight, height velocity, and weight velocity: British children, 1965. Part II. Arch Dis Child 1966; 41: 613-35.

- Tanner J M, Lejarraga H, Cameron N. The natural history of the Silver-Russell syndrome: a longitudinal study of thirty-nine cases. Pediatr Res 1975; 9: 611-23.

7 Shalet S M, Beardwell C G, Pearson D, Morris Jones $P$ H. The effect of varying doses of cerebral irradiation on growth hormone production in childhood. Clin Endocrinol (Oxf) 1976; 5: 287-90.

8 Frasier S D. Growth hormone stimulation tests in children. In: Raiti S, ed. Advances in human growth hormone research. Bethesda, Md: US Department of Health, Education, and Welfare, 1974: 632-57.

9 Shalet S M, Beardwell C G, Morris Jones P H, Pearson D. Growth hormone deficiency after treatment of acute leukaemia in children. Arch Dis Child 1976; 51 : 489-93.

10 Dacou-Voutetakis C, Haidas St, Zannos-Mariolea L. Letter: Radiation and pituitary function in children. Lancet 1975; ii: 1206-7.

Correspondence to Dr N K Griffin, The Hospital for Sick Children, Great Ormond Street, London WC1N 1EH.

Received 8 August 1979 